\title{
Gaining access to shiftworkers through labor unions
}

\author{
GLORIA C. GORDON, DONALD I. TEPAS \\ CYNTHIA G. STOCK, and JAMES K. WALSH \\ Saint Louis University, Saint Louis, Missouri 63103
}

In this paper, we provide the procedures used to gain access to shiftworkers who served as subjects in a work-sleep study. Our experiences in gaining the cooperation of labor union organizations and their members are described in detail, as are characteristics of the surveyed workers.

The work-sleep study is a multiple-method research program designed to identify likely relationships among work shift schedule, sleep, and off-the-job life variables in samples of American workers. In using the term "workers," we refer to men and women who are hourly employees working in industry and business. The worksleep study is an attempt to identify factors common to these workers in their sleeping and waking lives, regardless of occupation, industry, or location. Three principal methodologies, sequentially arranged, are used in the overall study: a survey; a laboratory study of sleep, performance, and mood; and a field interview. These three methodologies were closely coordinated in our Saint Louis sample of the work-sleep study with the intention of obtaining a comprehensive and reliable picture of shiftwork effects.

The focus of this paper is to describe our general approach and experience in contacting Saint Louis labor unions and collecting survey data from their members. Walsh, Gordon, Maltese, McGill, \& Tepas (1979) describe the laboratory and field interview techniques used in the study.

The work-sleep study differs in several ways from previous shiftwork research in this country. Typical real-world shiftworkers have not been studied in the United States with laboratory methods, although European investigators have used this population in both physiological and behavioral investigations (Akersted, Patkai, \& Dahlgren, 1977; Colquhoun \& Edwards, 1970; Foret \& Lantin, 1972; Patkai, Akerstedt, \& Pettersson, 1977). Survey or record studies that have sampled American shiftworkers have usually

This research was supported by Grant 5 RO1 OH 00395 from the National Institute for Occupational Safety and Health to Donald I. Tepas and by Postdoctoral Research Fellowship 5 F32 MH 05690 from the National Institute of Mental Health to Gloria C. Gordon. Reprints may be requested from Gloria C. Gordon, Department of Psychology, Saint Louis University, 221 North Grand, Saint Louis, Missouri 63103. The current address for D. L. Tepas and J. K. Walsh is the Department of Psychology, Illinois Institute of Technology, Chicago, Illinois 60616. The work-sleep study staff greatly appreciate the cooperation of the participating unions and union members from the Saint Louis metropolitan area. been conducted under the auspices of, or in conjunction with, employers (Mott, Mann, McLoughlin, \& Warwick, 1965; Tasto, Colligan, Skjei, \& Polly, Note 1). Unfortunately, female and minority group workers have not been represented in earlier work, and previous studies have tended to employ only one general method of data collection (Mott et al., 1965). The design of the worksleep study reflects an attempt to respond to these shortcomings.

A key element in the design of the present study is that workers were approached through labor unions rather than through employers. We chose to explore this path for obtaining participants in view of contradictory research findings concerning shiftwork as an occupational health hazard (Taylor, 1967, 1973; Levine, Note 2). It seemed reasonable to consider that the research results might be affected by the expectations of the data collectors and the setting in which the research was conducted (Milgram, 1963; Ome \& Evans, 1965; Rosenthal, 1966). Workers sometimes suspect that studies conducted in conjunction with management may affect their jobs in a negative way. Gaining access to workers through labor unions might be expected to yield a different perspective.

In addition to gaining workers' trust and minimizing the possible influence of management bias upon the data, a cooperative effort with unions seemed to be at least as suitable as the more conventional approach of working with management. Unions can provide access to workers from a broad range of occupations and work settings, and thereby minimize potential work-placespecific artifacts. Unions as institutions provide a natural structure and location for the collection of more generalizable data. Unions also represent a concemed sector of the community and may be the most receptive audience for findings resulting from shiftwork studies.

\section{WORK-SLEEP SURVEY}

Unions were asked for assistance in recruiting members to fill out the Work-Sleep Survey. This survey is a concise four-page questionnaire that takes $15-20 \mathrm{~min}$ for most workers to complete and requests basic 
information on type of work, hours of work, hours of sleep, health, drug use, and related matters. The survey allowed us to gather these data from a relatively large and diverse sample of workers; it also provided a way for workers to indicate whether they had further interest in the laboratory and interview phases of the study by filling in name, address, and phone number at the end of the survey. Workers with no interest in other parts of the study could complete the survey anonymously. The Work-Sleep Survey was completed by 1,442 workers from the Saint Louis metropolitan area. This group constitutes the survey sample discussed in this report. Respondents in the sample who indicated an interest in the other two phases of the study are referred to as survey volunteers.

The survey volunteers provided a pool from which to select up to 120 participants for the laboratory study, depending upon the availability of volunteers with specific job and demographic characteristics. The goal of the laboratory study was to include equal numbers of male and female workers representing three different shift schedules: steady first shift (approximately 8:00 a.m. to 4:00 p.m.). steady third shift (approximately $12: 00 \mathrm{a} . \mathrm{m}$. to $8: 00 \mathrm{a} . \mathrm{m}$.), rotating shift (working two or three different shift schedules within a month), and a fourth group that was undergoing an acute change from one steady shift to another. Within each of the four groups, we sought two levels of on-thejob physical exertion: relatively heavy physical work and work of a more sedentary nature.

Information on the Work-Sleep Survey was used to select workers from the pool of survey volunteers to fill the groups specified by the laboratory study design, and to meet certain constraints imposed by the nature of polysomnographic research. We chose to define several important variables, such as physical exertion on the job or relative drug use, on the basis of data collected from the first 400 surveys, as an indication of the conditions that prevailed in the population.

\section{CONTACTING LABOR UNIONS}

The general style or climate of our approach to unions and their members can be summarized by a set of seven overlapping characteristics: (1) No promises were made to unions concerning the nature of our findings. Emphasis was placed upon our integrity as independent researchers interested in making an objective evaluation. (2) Unions were approached with a positive attitude toward the function of organized labor as an institution in our society. The union label was displayed on all of our commercially printed materials. We assumed that unions with shiftworkers would have an interest in the study. The general findings were to be presented to the cooperating unions for their possible future use in improving the well-being of workers. (3) The trust and advice of union leaders were sought. We worked through the official leadership of each union. No contacts were sought with any employer. (4) All dimensions of the research program were fully disclosed to the cooperating unions; background information was provided in correspondence, presentations, and a four-page explanatory brochure. (5) Emphasis was placed on the voluntary nature of individual participation. Informed consent was obtained for each step in the study only after providing the participant with a complete description of that step. (6) The identity of participants in all phases of the research was confidential; participation was disclosed to no one, including the unions. The names of employers were not formally recorded with the data. The identity of cooperating unions was disclosed only with their permission. (7) Personal contact was maintained with union leaders and members throughout the course of their participation.

The first step in contacting the organized labor community in Saint Louis was to pay courtesy and advice-seeking calls on several key people, such as officials of the AFL-CIO Council and the editor of an independent weekly labor newspaper. These individuals suggested the unions with shiftworkers and provided information on the proper official to contact within each union. After many appointments, letters to union leaders, follow-up phone calls, and more appointments, the first union agreed to participate in the work-sleep study. Once this event occurred, there appeared to be a snowball effect, with each cooperating union leading to another. Articles on the purpose and method of the study in the publications of cooperating unions and in the two Saint Louis daily newspapers, and interviews on radio talk shows added to the visibility of the study and helped to obtain further cooperation.

Making effective contact with the unions required knowing and meeting the appropriate officer or staff member for initial contact in each case, since organizational structure differs widely among unions. Decision processes and the degree of participation by officers and members also vary. We found it effective to contact about one-third of the international unions at the district level, and the rest at the local or lodge level.

In approaching each union, we asked to be invited to a membership meeting to present a short address and administer the Work-Sleep Survey. A brisk and lively talk was developed for union meetings, with emphasis on the strict confidentiality and voluntary nature of participation. The research program and pertinent background information on shiftwork were described as completely as time allowed, and an explanatory brochure was distributed. Union members were urged to complete the survey, whether or not they were interested in further participation. It was explained that those completing the laboratory phase of the study would receive an honorarium of $\$ 100$.

Unions were encouraged to suggest additional or 
alternative ways to contact the membership because of the frequent low attendance at meetings. A number of unions offered to have shop stewards distribute the survey. Self-administering, confidential packets were provided for this purpose. Unions were also requested to inform members of the study through union publications and bulletin board notices.

A typical example of union interaction began with an introductory letter from us. An in-person presentation to union leaders took place in about one-third of the cases prior to attending a union membership meeting. Typically, unions invited a staff member to attend a membership meeting after about four separate contacts, although some unions extended the invitation after only one or two letters or phone calls. At the other extreme, one union required about 20 telephone calls and 15 letters, assisted midway by an introduction from an official of a cooperating union, before the officials agreed to participate.

\section{RESPONSE BY UNIONS AND WORKERS}

A total of 35 Saint Louis area locals and lodges, belonging to 17 intemational unions, participated in the study. These unions constitute about $85 \%$ of those we contacted. Another $10 \%$ refused our request immediately; $5 \%$ rejected the study after consideration by their executive boards. The immediate refusals appeared to come from unions that tended to refrain from involvement in nonunion matters of any sort.

The cooperating unions represented a wide variety of occupations, including blue collar, white collar, and service workers. A sample list of occupations includes telephone operators, bakers, punch-press operators, printers, clerical workers, utility crew members, machinists, factory assemblers, and postal workers. Most of the unions included workers from many employers and employment locations, thus representing an indeterminate but large number of industries and plants in the full survey sample.

In response to our request, almost all of the participating unions invited a staff member to attend at least one union meeting. In the optimal situation, about $45 \mathrm{~min}$ of the meeting was set aside for our presentation and completion of the Work-Sleep Survey by interested members. Fifteen locals made arrangements for the survey to be distributed to members by shop stewards or union officers. Other methods used by several unions included placing advertisements with coupons in their publications, sending a mailing to their entire membership, and helping us to distribute the survey at places of employment.

Through these routes of access to individuals, the 1,442 surveys were collected. Of these, $76 \%$ were gathered by our staff at union meetings, $15 \%$ through distribution by stewards and officers, $5 \%$ through direct mailing by the union, and small percentages by other methods. We obtained a mean response rate of $69 \%$ at 31 of the union meetings where the survey was administered. Of the 1,442 workers who completed surveys, $997(69.1 \%)$ agreed to become survey volunteers. The various routes of access to union members yielded survey volunteers in percentages similar to those indicated for the full survey sample.

\section{CHARACTERISTICS OF SURVEYED WORKERS}

The data presented below describe the sample in terms of certain job and demographic characteristics and also demonstrate that the survey volunteers do not differ significantly from the survey sample along these dimensions.

The distributions by work shift of the survey sample and survey volunteers are shown in Table 1 . The majority of respondents were first-shift workers. The percentages of workers on each shift were not significantly different in the two samples. Approximately $40 \%$ of the samples worked a shift other than the first. This figure is about $10 \%-15 \%$ higher than the estimated proportion of non-first-shift workers in the United States work force (Tasto \& Colligan, Note 3). The inflated number of non-first-shift workers in our sample most likely reflects our intentional selection of unions containing substantial numbers of shiftworkers.

Most of those surveyed had worked on their reported schedules for at least 1 year, and about half had worked

Table 1

Percentages of Survey Sample and Survey Volunteers by Job and Demographic Variables

\begin{tabular}{lrr}
\hline & $\begin{array}{c}\text { Survey } \\
\text { Sample }\end{array}$ & $\begin{array}{c}\text { Survey } \\
\text { Volunteers }\end{array}$ \\
\hline Sex & & \\
Male & 78.3 & 79.2 \\
Female & 21.7 & 20.8 \\
Marital Status & & \\
Married & 73.6 & 72.1 \\
Single & 13.1 & 13.4 \\
Divorced & 8.0 & 8.8 \\
Separated & 2.7 & 3.4 \\
Widowed & 2.6 & 2.3 \\
Education & & \\
High School & 75.2 & 76.3 \\
College & 3.7 & 3.3 \\
Technical School & 15.6 & 17.0 \\
Work Shift & & \\
First & 62.0 & 59.2 \\
Second & 10.9 & 12.3 \\
Third & 9.5 & 10.8 \\
Rotating & 17.6 & 17.7 \\
Years on Shift & & \\
1-5 & 28.3 & 29.3 \\
5+ & 51.3 & 49.5 \\
\hline
\end{tabular}

Note-For the survey sample, $N=1,442$; for the survey volunteers, $N=997$. Figures for education represent percentages that graduated at each level, including those who also graduated at a higher level. 
on their reported shifts for more than 5 years (see Table 1). The survey volunteers showed similar shift history data. These shift durations suggest that our approach through unions gained access to workers with sufficient shift tenure to demonstrate potential longrange shift schedule effects.

The survey sample and survey volunteers are further described in Table 1 by sex, marital status, and educational level. None of the percentages for the two samples was significantly different. The mean age for the survey sample (mean $=39.4$ years) and the survey volunteers (mean $=38.8$ years) did not differ significantly. The average size of the household was three to four persons for both samples.

From these data, we conclude that we succeeded in obtaining survey information from a group of seemingly typical American workers. Furthermore, those who volunteered for the laboratory and field interview phases of the study appear representative of the survey sample in several basic characteristics.

\section{COMMENT}

As a way to gain access to shiftworkers through unions, a viable model has been presented for cooperation on an issue of mutual interest to academic researchers, union leaders, and union members. It appears that many unions will cooperate in research endeavors and that many active union members are willing to participate as subjects at one level or another. Of course, the climate and handling of contacts between unions and researchers is important. Our ability to obtain the trust and confidence of union officers and members resulted not only in a satisfactory rate of participation, but also in a sincere effort by the volunteers to provide complete and accurate information.

Workers who volunteered for further research participation appear to have been representative of the full survey sample along certain key dimensions. We are not certain, however, how our survey sample compared with the full population of members in the unions that cooperated. A minority of union members regularly attend meetings in most locals, and the majority of our surveys were completed by individuals at union meetings. It is possible that those who do not regularly attend union meetings are the very workers who are most heavily burdened by the shiftwork factors under study. Finally, the extent to which our data can be generalized to non-union members is unknown; union members constitute only about one-quarter of the United States work force.

The degree to which our methods for soliciting union cooperation would be successful in other locations remains to be determined. Since Saint Louis has a higher proportion of union members than many other cities, organized labor may be a more viable source of participants in this area than in less organized areas of the country.

While the issues mentioned above are important, they need not deter future endeavors of this type. Our experience suggests that researchers can interact with and rely upon organized labor to cooperate in studies that can yield valuable information about the effects of shiftwork, health, and well-being.

\section{REFERENCE NOTES}

1. Tasto, D. L., Colligan, M. J., Skjei, E. W., \& Polly, S. J. Health consequences of shift work. DHEW (NIOSH) Publication No. 78-154, 1978.

2. Levine, H. Health and work shifts. In P. G. Rentos \& R. D. Shepard (Eds.), Shift work and health. DHEW (NIOSH) Publication No. 76-203, 1976.

3. Tasto, D. L.. \& Colligan, M. J. Shift work practices in the United States. DHEW (NIOSH) Publication No. 77-148, 1977.

\section{REFERENCES}

Akersted, T., Patkai, P., \& Dahlgren, K. Field studies of shiftwork: Il. Temporal patterns in psychophysical acivation in workers alternating between night and day work. Ergonomics, 1977, 20, 621-631.

Colquhoun, W.P., \& Edwards, R. S. Circadian rhythms of body temperature in shift workers at a coalface. British Journal of Industrial Medicine, 1970, 27, 266-272.

FORET, J., \& LANTIN, G. The sleep of train drivers: An example of the effects of irregular work schedules on sleep. In W. P. Colquhoun (Ed.), Aspects of human efficiency. London: English Universities Press, 1972.

Milgram, S. Behavioral study of obedience. Journal of Abnormal and Social Psychology, 1963, 67, 371-378.

Mott. P. E.. Mann, F. C., Mcloughin, Q., \& Warwick, D. P. Shift work. Ann Arbor: University of Michigan Press, 1965.

ORne, M. T., \& Evans, F. J. Social control in the psychological experiment: Antisocial behavior and hypnosis. Journal of Personality and Social Psychology, 1965, 1, 189-200.

Patkai, P., Akerstedt, T., \& Petrersson, K. Field studies of shiftwork: I. Temporal patterns in psychophysiological activation in permanent night workers. Ergonomics, 1977, 20, $611-619$.

Rosenthal, R. Experimenter effects in behavioral research. New York: Appleton-Century-Crofts, 1966.

TAYLOR. P. J. Shift and day work: A comparison of sickness absence, lateness, and other absence behavior at an oil refinery from 1962 to 1965 . British Joumal of Industrial Medicine, 1964, 24, 93-102.

TAYLOR, P. J. The effects of shift work on worker health. Industrial Medicine and Surgery, 1973, 42, 13-19.

Walsh, J. K., Gordon, G. C., Maltese, J. W., McGill, W. L., \& TEPAS, D. I, Laboratory and field interview methods for the study of shiftworkers. Behavior Research Methods \& Instrumentation, 1979. 11, 18-23. 